
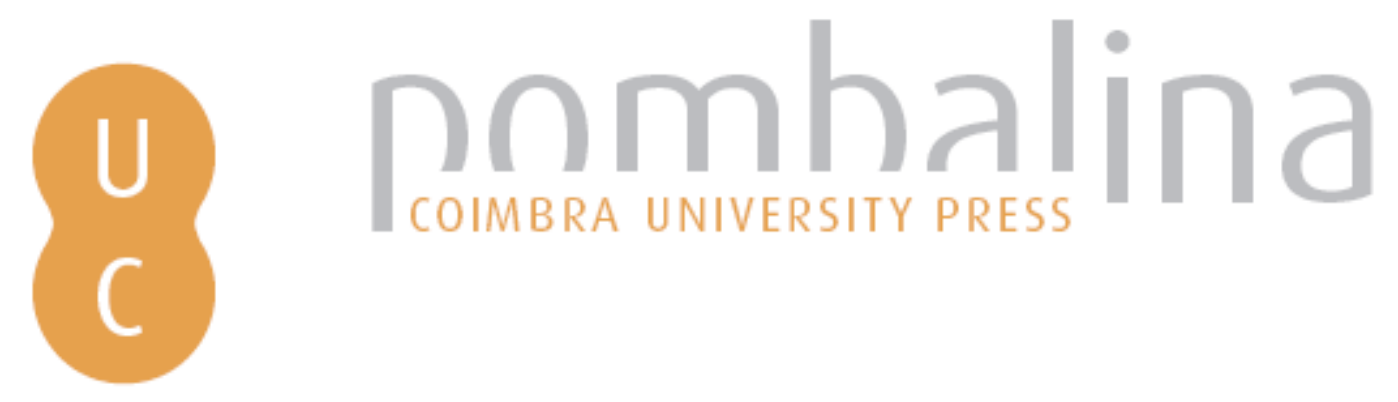

\title{
Guia metodológico para a cartografia de risco: um produto do diálogo ciência/utilizadores
}

\author{
Autor(es): $\quad$ Julião, Rui Pedro \\ Publicado por: Imprensa da Universidade de Coimbra \\ URL \\ persistente: URI:http://hdl.handle.net/10316.2/35749 \\ DOI: $\quad$ DOI:http://dx.doi.org/10.14195/978-972-8330-23-1_4 \\ Accessed : $\quad$ 26-Apr-2023 11:28:40
}

A navegação consulta e descarregamento dos títulos inseridos nas Bibliotecas Digitais UC Digitalis, UC Pombalina e UC Impactum, pressupõem a aceitação plena e sem reservas dos Termos e Condições de Uso destas Bibliotecas Digitais, disponíveis em https://digitalis.uc.pt/pt-pt/termos.

Conforme exposto nos referidos Termos e Condições de Uso, o descarregamento de títulos de acesso restrito requer uma licença válida de autorização devendo o utilizador aceder ao(s) documento(s) a partir de um endereço de IP da instituição detentora da supramencionada licença.

Ao utilizador é apenas permitido o descarregamento para uso pessoal, pelo que o emprego do(s) título(s) descarregado(s) para outro fim, designadamente comercial, carece de autorização do respetivo autor ou editor da obra.

Na medida em que todas as obras da UC Digitalis se encontram protegidas pelo Código do Direito de Autor e Direitos Conexos e demais legislação aplicável, toda a cópia, parcial ou total, deste documento, nos casos em que é legalmente admitida, deverá conter ou fazer-se acompanhar por este aviso.

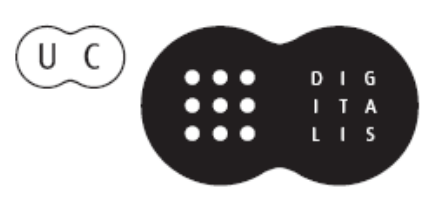




\section{REALIDADES E DESAFIOS NA GESTÃO DOS RISCOS}

\section{Diálogo entre Ciência e Utilizadores}

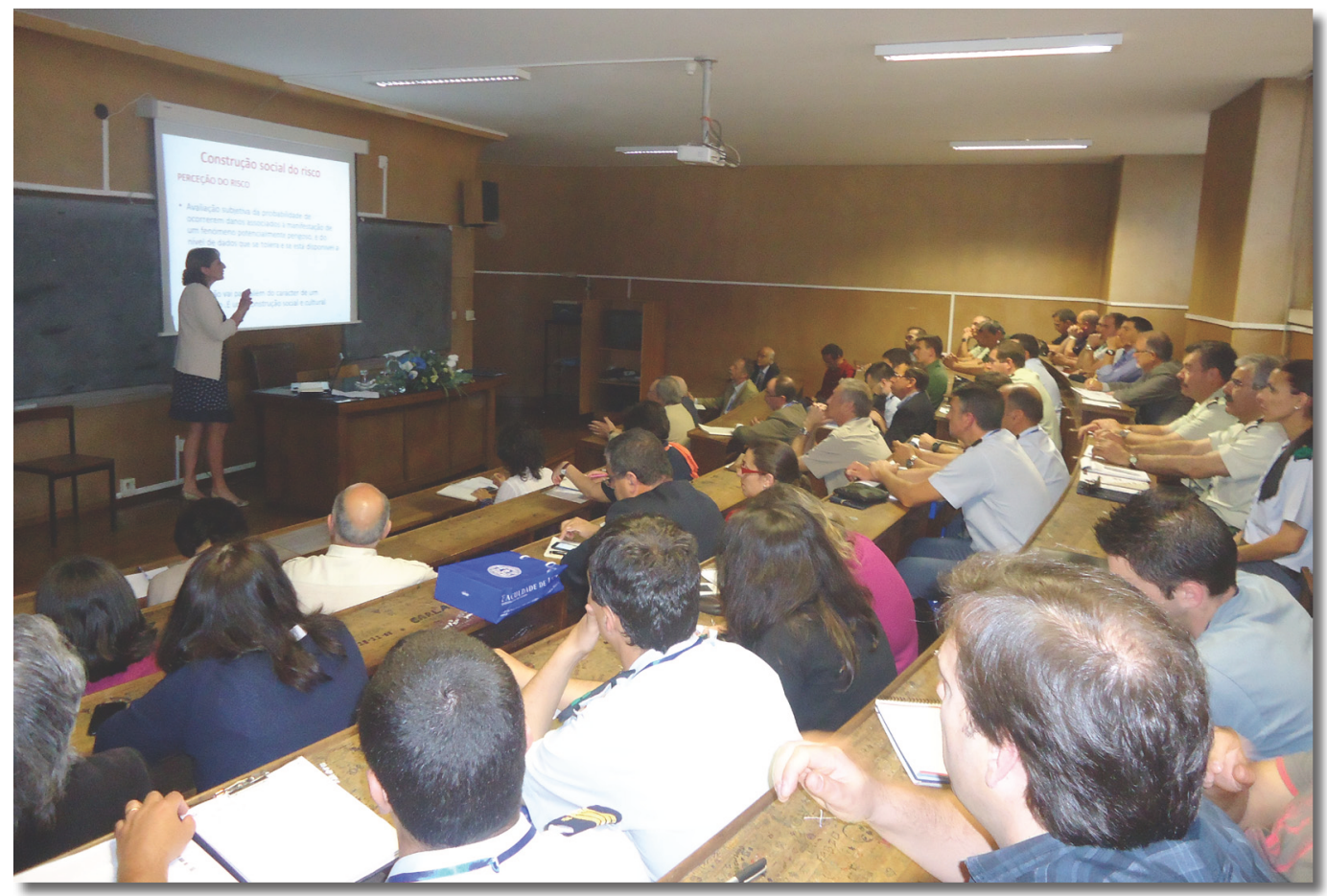

Núcleo de Investigação Científica de Incêndios Florestais

Faculdade de Letras da Universidade de Coimbra

Coimbra 


\title{
Capítulo IV
}

\section{GUIA METODOLÓGICO PARA A CARTOGRAFIA DE RISCO. UM PRODUTO DO DIÁLOGO CIÊNCIA/UTILIZADORES}

\author{
Rui Pedro Julião \\ e-GEO - Centro de Estudos de Geografia e \\ Planeamento Regional FCSH/UNL
}

rpj@fcsh.unl.pt

\section{Introdução}

O Território é a base espacial de suporte de qualquer Sociedade, conferindo-lhe parte da sua identidade e proporcionado recursos e oportunidades, e como tal, desde sempre foi importante para o Homem.

As intervenções humanas, em diferentes locais do globo, nas mais variadas escalas e pelas mais variadas razões - mas sobretudo devido ao desenvolvimento tecnológico - registaram, desde a segunda metade do século passado, uma acentuada transformação, quer pelo seu ritmo que acelerou e intensidade que aumentou, quer pelo significado da sua extensão territorial que se expandiu. As transformações espaciais realizaram-se, em muitos casos, a ritmos superiores à capacidade de análise, interpretação e correção por parte do próprio Homem, criando uma série de situações de crise (JuLı̃̃o, 2001).

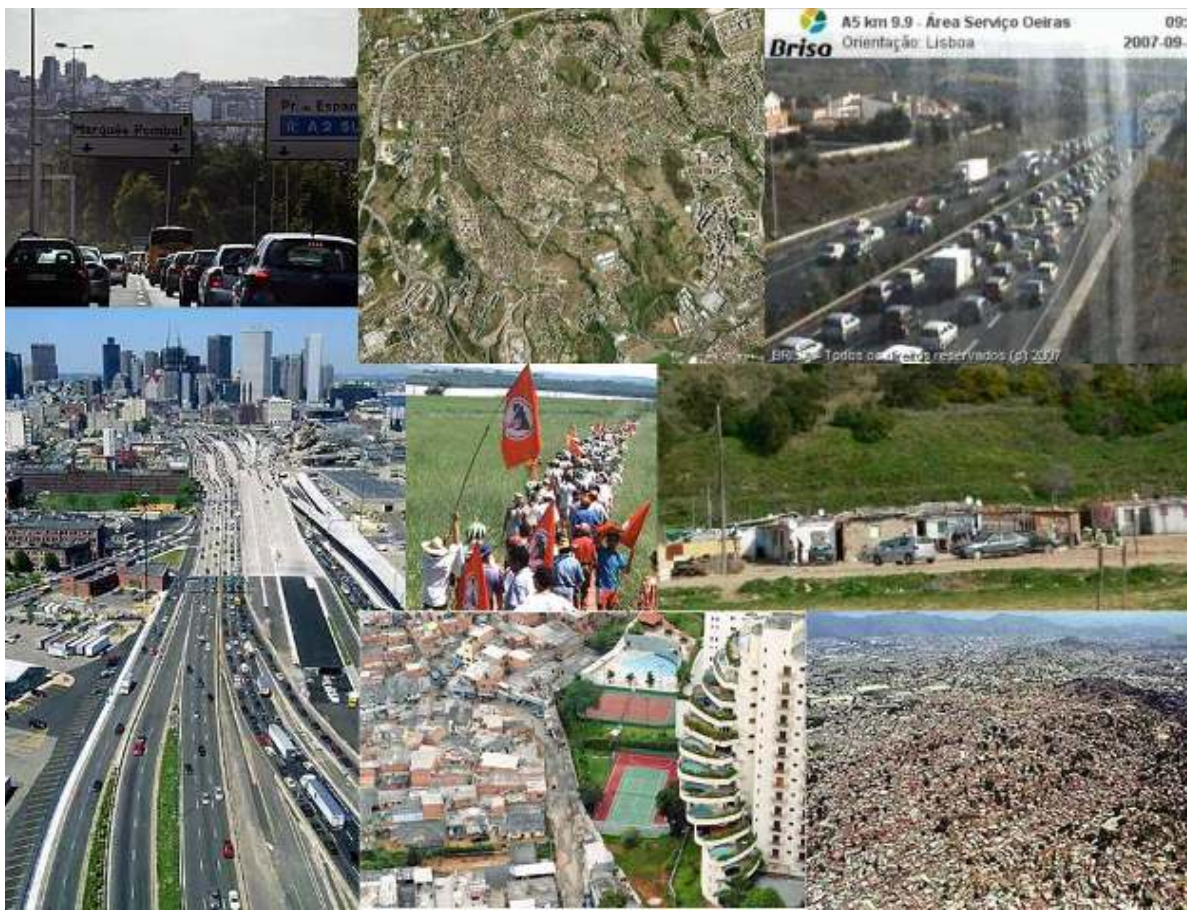

Fig. 1 - Estruturas territoriais complexas.

A dinâmica demográfica e urbana dos grandes centros urbanos sofreu nos últimos 50 anos uma forte acentuação, por via de crescimento natural, mas sobretudo por via de migrações (internas e externas). Como resultado, a pressão sobre o território das áreas mais atrativas atingiu níveis 


\section{Realidades e desafios na gestão dos riscos \\ - Diálogo entre ciência e utilizadores -}

críticos, com a produção de estruturas territoriais cada vez mais complexas e contrastadas, e também se geraram fenómenos de ocupação irregular do espaço, muitas vezes sem a garantia das condições mínimas de habitabilidade e sem o necessário respeito pelas condições ambientais. Consequentemente, foram produzidos territórios "insustentáveis" (entre aspas, dada a prevalência e mesmo crescimento de alguns deles ao longo dos últimos anos) do ponto de vista físico, humano e social.

A Organização das Nações Unidas (ONU) estima que cerca de $50 \%$ da população habite em áreas urbanas, com uma previsão na ordem dos $70 \%$ para 2020 , sendo que um terço o faz em áreas sem condições, designadas em língua Portuguesa por favelas, bairros de lata, musseques ou caniços. Chama também a atenção para a necessidade de analisar de forma cuidada e prospetiva a situação referindo que "Cities must create the conditions (and record accurate data) that will enable them to understand and anticipate trends, including the growth or decline of some areas or regions, if they are to be in a position to develop expansionary or recovery strategies" (UN-HABITAT, 2012: 26).

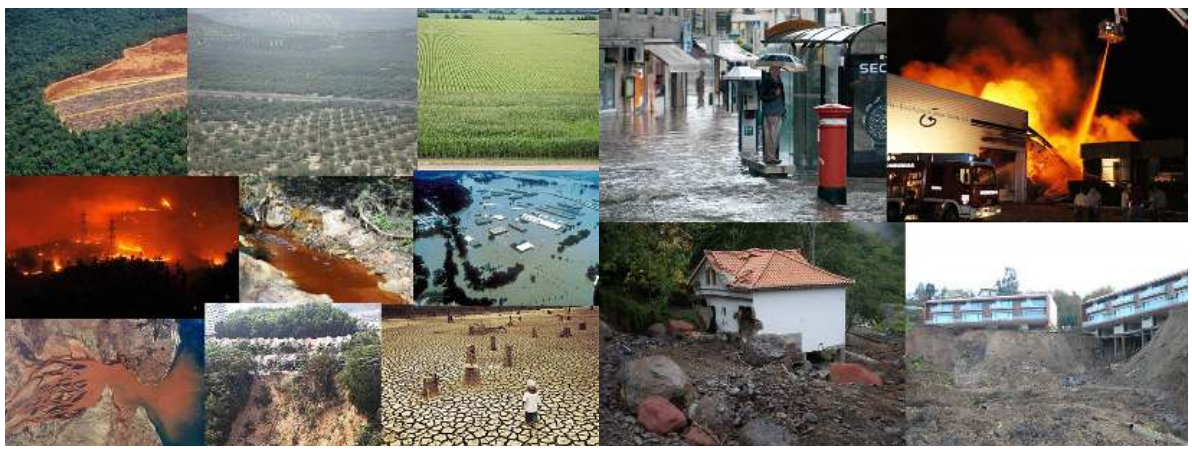

Fig. 2 - Exposição a vários fenómenos e perigos de diferentes tipologias.

Para além dos sobejamente conhecidos problemas das grandes cidades e respetivas áreas metropolitanas, também os restantes territórios se encontram expostos a fenómenos e perigos da mais variada natureza e tipologia, como é o caso das áreas rurais, das áreas litorais e também das grandes áreas de paisagem natural e/ou seminatural.

Por isso, todos os intervenientes nos processos de gestão e decisão territorial, nos seus múltiplos aspetos (físicos e humanos), sentem cada vez mais maiores dificuldades para conjugar a multiplicidade de perspetivas necessárias para uma abordagem territorial integrada e coerente. Essa conjugação é, no entanto, um passo imprescindível para a coordenação das diferentes ações, no sentido de se minimizarem os efeitos negativos de intervenções isoladas ou da falta de perceção dos potenciais impactes territoriais das decisões tomadas. Como salienta
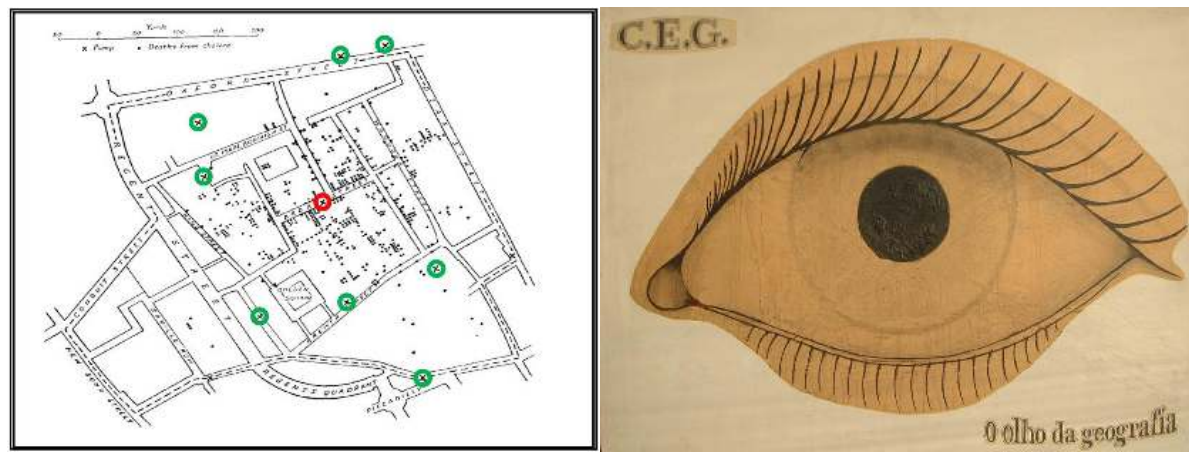

Fig. 3 - Metodologias e tecnologias “do passado". 


\section{Guia metodológico para a cartografia de risco. \\ Um produto do diálogo ciência/utilizadores}

FERRão (2011:40) há a necessidade de uma "nova concepção de Ordenamento do Território na promoção de uma maior integração das políticas sectoriais, tendo como referências visões partilhadas de base territorial".

Podemos assim dizer que, prevalecendo no essencial válidas, as metodologias e tecnologias "do passado", carecem da capacidade de suportar a nova forma e atuar no domínio da gestão territorial que implica necessariamente considerar e articular as múltiplas perspetivas e interesses que nele se conjugam, em tempo real e prospetivo, o que, no atual contexto, marcado por uma escassez de recursos, torna ainda mais determinante considerar-se estas perspetivas e interesses de uma forma integrada. Ou seja, importa reforçar o conceito e a prática de uma gestão territorial integrada, onde a informação é base do conhecimento de situação, suporte do planeamento e programação, bem como fundamento das decisões que em cada momento devem ser tomadas.

\section{Gestão Territorial e Informação}

Quando se fala da gestão integrada do território, efetua-se a fusão de dois conceitos chave.

O da "gestão" como o conjunto de tarefas que procuram garantir a afetação eficaz de todos os recursos disponibilizados a fim de serem atingidos os objetivos pré-determinados. Ou seja, a otimização do funcionamento, neste caso de um determinado território, através da tomada de decisões racionais e fundamentadas na recolha e tratamento de dados e informação relevante e, por essa via, contribuir para o seu desenvolvimento e para a satisfação dos interesses e necessidades dos seus atores e agentes no geral ou de um grupo em particular.

Mas não se trata de uma gestão individualizada, potencialmente ad-hoc, mas sim integrada. Ou seja, articulando as várias componentes do território e as diferentes perspetivas e interesses que os stakeholders têm sobre ele.

Resumindo, quando se fala de gestão integrada do território, fala-se efetivamente de um conjunto de políticas públicas articuladas que devem criar as condições de base para que, através das suas componentes instrumentais, se promova o desenvolvimento sustentável da sociedade.

No que se refere ao conjunto de políticas de Ordenamento do Território, houve a preocupação em criar uma base organizada que está materializada no PNPOT - Programa Nacional da Política de Ordenamento do Território, aprovado pela Lei n. ${ }^{\circ} 58 / 2007$, de 4 de setembro, que vem estabelecer um quadro orientador para os diferentes instrumentos de gestão territorial, bem como preconizar a necessidade de estes se suportarem em conjuntos de dados geográficos relevantes (MAOTDR, 2007).

Retomando a definição de gestão, é importante frisar que na mesma se dá particular destaque à necessidade de esta ser um conjunto de tomada de decisões racionais e fundamentadas na recolha e tratamento de dados e informação relevante. Ou seja, boa gestão pressupõe boa informação.

Sobre esta questão importa refletir sobre o papel da informação como base material para o estabelecimento e desenvolvimento de um quadro normativo de gestão integrada do território, pois sem antes possuir um conhecimento cabal do mesmo, através de informação integrada do território, tal não parece viável.

Ao invés do domínio das políticas públicas sobre ordenamento e gestão territorial, certo é que nem sempre reveladoras de um espírito integrador, no domínio da informação de base territorial verifica-se uma situação de ausência de políticas públicas consolidadas, quer no que se refere aos dados, quer no que se refere aos instrumentos.

Tal facto tem consequências graves na existência e disponibilidade de conjuntos de dados geográficos relevantes para suportar de forma adequada ações necessárias para uma correta e eficaz gestão integrada do território. 


\section{Realidades e desafios na gestão dos riscos \\ - Diálogo entre ciência e utilizadores -}

Mas a produção de dados geográficos integrados sobre o território baseia-se nalguns pressupostos de base que começam a ficar consolidados muito pelo esforço desenvolvido no plano internacional, mais do que no nacional.

A aprovação da Diretiva INSPIRE (Diretiva 2007/2/EC, do Parlamento Europeu e do Conselho, de 14 de março de 2007) e respetiva regulamentação, onde se incluem modelos de dados para um significativo conjunto de temas relevantes (ver http://inspire.jrc.ec.europa.eu/), a criação e aprovação de um conjunto de especificações ISO da família 19100 e o reconhecimento dos standards Open Geospatial Consortium por parte da esmagadora maioria dos fornecedores de tecnologia, criaram as condições mínimas para um ambiente de produção, gestão e disponibilização de dados geográficos interoperáveis.

No plano conceptual e tecnológico assiste-se a uma clara mudança de paradigma. 0 paradigma de cloud computing, preconizando a existência e a utilização de recursos distribuídos acessíveis através da Internet, tem hoje condições para se expandir ao domínio da informação geográfica e com efeito isso tem acontecido. Hoje é cada vez mais importante falar de Infraestruturas de Dados Espaciais (IDE) em vez de projetos SIG.

As IDE dão, a cada utilizador, a garantia de estar a aceder à informação de melhor qualidade (posicional, topológica e temporal) diretamente a partir do seu produtor. Mais, essa informação, uma vez que é produzida e disponibilizada de acordo com standards reconhecidos, é passível de ser diretamente integrada com outros dados que já existam localmente ou oriundos de diferentes produtores.

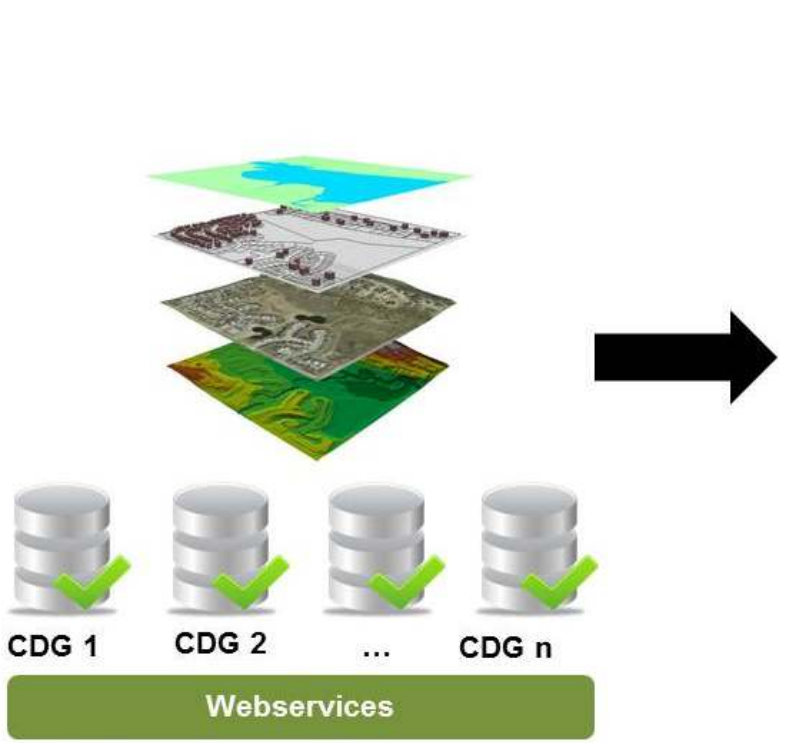

Fig. 4 - Boa gestão implica boa informação.

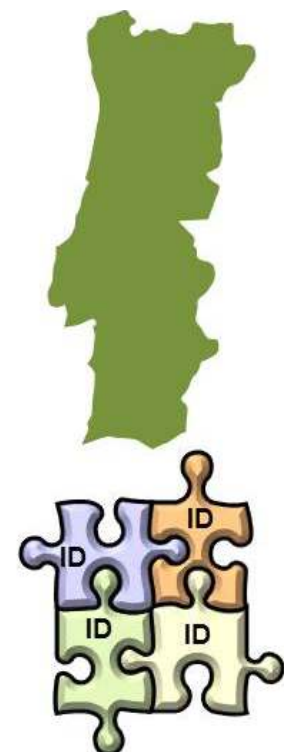

A representação estática do território (digital ou analógica) referente a um determinado momento temporal dos elementos que correspondem a um catálogo de objetos pré definido, base dos processos tradicionais de produção cartográfica, está claramente ultrapassada pela produção e atualização de conjuntos de dados geográficos determinados em função das necessidades dos utilizadores. A carta deixa de ser a base do processo de trabalho para ser o instrumento de comunicação do resultado das análises e decisões propostas. Morreu a "velha" cartografia, viva a "nova" geografia!

Sem uma verdadeira base de informação integrada sobre o território, não se pode promover a sua eficiente gestão. Já no âmbito do relatório do PNPOT foi identificado como um dos vinte e quatro problemas para o Ordenamento do Território a "Insuficiência das bases técnicas 


\section{Guia metodológico para a cartografia de risco. Um produto do diálogo ciência/utilizadores}

essenciais para o ordenamento do território, designadamente nos domínios da informação geo-referenciada sobre os recursos territoriais, da cartografia certificada, da informação cadastral e do acesso em linha ao conteúdo dos planos em vigor" (MAOTDR, 2007: 107). Ideia reforçada por Ferrão (2011:40) quando diz que assim, não é possível construir "visões partilhadas de base territorial".

\section{Guia Metodológico}

No contexto anteriormente enunciado e considerando que as sociedades contemporâneas, as populações, exigem um elevado nível de segurança e bem-estar nos espaços públicos e equipamentos urbanos, nas áreas industriais e nas comunicações, bem como a preservação da qualidade do ambiente, a avaliação e a caracterização metódica dos riscos naturais, tecnológicos e mistos é um dos passos fundamentais para o adequado desenvolvimento dos processos de planeamento de emergência e de ordenamento do território.

Também, do processo contínuo de revisão dos Planos Diretores Municipais (PDM) e dos Planos Municipais de Emergência (PME) a decorrer ao nível nacional, emerge a necessidade da existência de uma metodologia para a elaboração da cartografia de risco metodologicamente harmonizada e adequada princípios atuais de produção e disponibilização de dados geográficos.

Surgiu assim, o "GUIA METODOLÓGICO PARA A PRODUÇÃO DE CARTOGRAFIA MUNICIPAL DE RISCO E PARA A CRIAÇÃO DE SISTEMAS DE INFORMAÇÃO GEOGRÁFICA (SIG) DE BASE MUNICIPAL”, editado em 2009, como uma resposta adequada dos serviços com responsabilidade diretas nas matérias chave, quer no domínio temático (ANPC e DGOTDU), quer no domínio dos dados e tecnologias (IGP).

Este guia é o produto de um trabalho conjunto de um grupo, coordenado pelo Instituto Geográfico Português (IGP) que reuniu especialistas da Autoridade Nacional de Proteção Civil (ANPC) e da Direcção-Geral do Ordenamento do Território e Desenvolvimento Urbano (DGOTDU), em estreita colaboração com uma equipa de peritos da academia portuguesa, oriundos de várias escolas e com diferentes domínios de formação/especialização: Universidade de Lisboa, Universidade de Coimbra e Universidade do Porto.
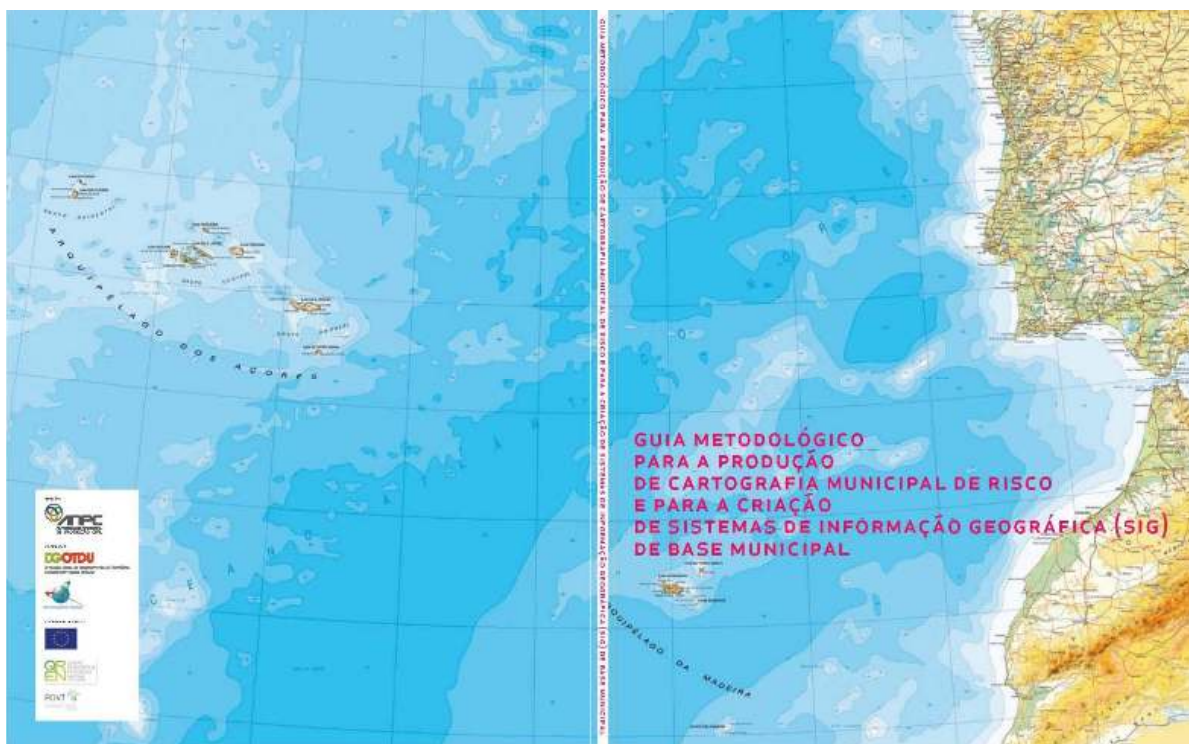

Fig. 5 - Guia Metodológico para a Produção de Cartografia de Risco. 


\section{Realidades e desafios na gestão dos riscos \\ - Diálogo entre ciência e utilizadores -}

O Guia Metodológico veio dar resposta aos objetivos prioritários estabelecidos pelos membros do Governo que criaram o grupo de trabalho, designadamente:

- Identificar e selecionar os tipos de perigos naturais, tecnológicos e mistos significativos a considerar na dupla vertente orientada para a análise e avaliação de riscos e para a definição das orientações metodológicas particulares na produção da cartografia;

- Definir normas técnicas para a produção de cartografia temática de risco de âmbito municipal, incluindo a harmonização dos conceitos, tipologias, designações e formas de representação gráfica;

- Definir orientações técnicas para a construção dos SIG de base municipal, no que respeita a levantamento, monitorização e validação dos dados sobre os riscos naturais e tecnológicos existentes, com o intuito de reforçar a prevenção e o apoio à decisão dos gestores municipais nas melhores soluções de ordenamento e de planeamento de emergência.

Em termos práticos, a solução preconizada pelo Guia Metodológico, é apresentada numa estrutura com um corpo principal, no qual, após um breve enquadramento inicial (capítulo 1), se definem os conceitos fundamentais a aplicar (capítulo 2), se identifica o conjunto global de riscos a partir do qual se fará a seleção dos riscos a cartografar em cada município (capítulo 3) e se explicitam os procedimentos a adotar para a produção da cartografia municipal de risco (capítulo 4). O último capítulo do guia estabelece as linhas de orientação para a criação dos SIG associados a esta temática (capítulo 5).

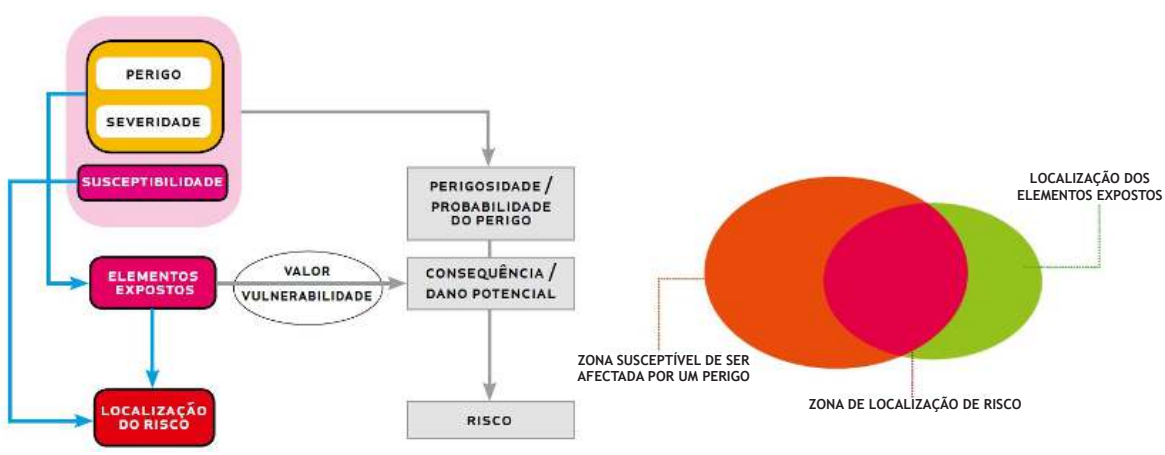

Fig. 6 - Abrangência do Guia.

São ainda providenciados dois importantes anexos onde se apresentam os aspetos metodológicos específicos para a produção das principais peças cartográficas (Cartas de Suscetibilidade e Cartografia de Elementos Estratégicos, Vitais e/ou Sensíveis). De salientar que para a produção do segundo anexo foi efetuado um exercício de compatibilização com o catálogo de objetos da série cartográfica oficial à escala 1:10 000 .

\section{Capacitação dos municípios}

Em Portugal a adoção das novas tecnologias associadas à informação geográfica foi, desde muito cedo, incentivada através de vários programas governamentais. Com efeito, a criação do Sistema Nacional de Informação Geográfica (SNIG) em 1990 e a sua posterior abertura à Internet em 1995, bem como um conjunto de outras iniciativas promovidas pelo Centro Nacional de Informação Geográfica (posteriormente integrado no Instituto Geográfico Português), criaram condições para a grande capacidade nacional e o reconhecimento internacional do nosso País. 


\section{Guia metodológico para a cartografia de risco.}

Um produto do diálogo ciência/utilizadores

Importa aqui destacar a significativa evolução registada pelos municípios. Desde as iniciativas pioneiras do PROGIP e do PROSIG, da década de 90, tem-se assistido à rápida consolidação das suas capacidades.

Se à época existiam pouco mais de uma dezena de exemplos, hoje a realidade é completamente diferente. Vários estudos, realizados nos últimos anos, mostram que há uma cobertura quase integral de utilização dos SIG por parte dos municípios portugueses (JuLião e QueIRós, 2009).

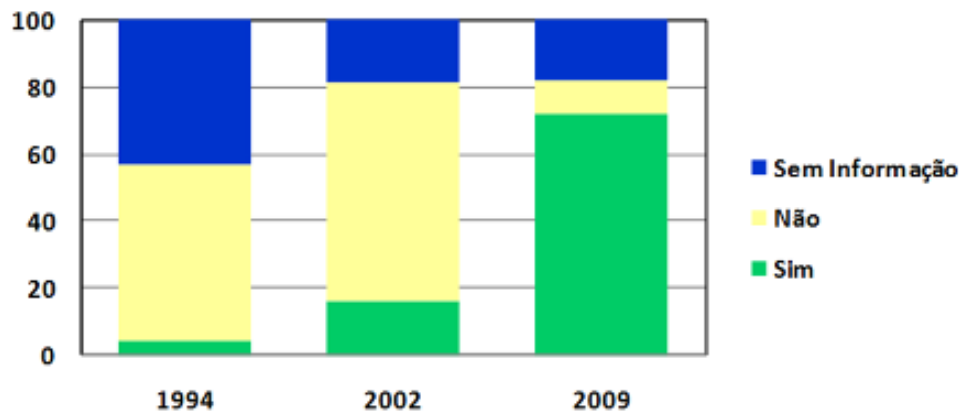

Fig. 7 - Evolução dos SIG nos municípios 1994-2009.

A realidade de utilização dos SIG por parte dos municípios evoluiu assim rapidamente ao longo das últimas três décadas.

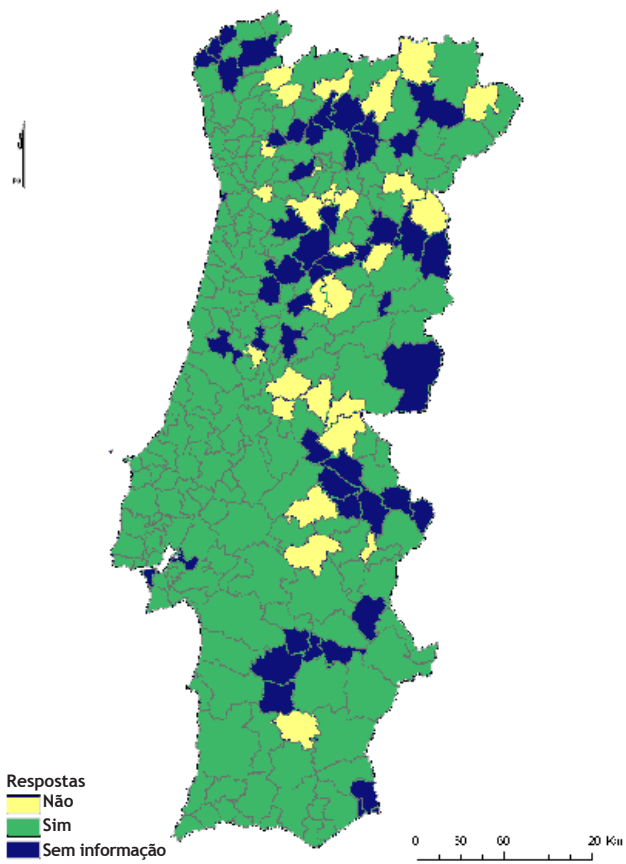

Fig. 8 -Distribuição geográfica da utilização dos SIG nos municípios em 2009. 


\section{Realidades e desafios na gestão dos riscos \\ - Diálogo entre ciência e utilizadores -}

Como muito bem se pode observar pela fig. 7 é possível considerar-se hoje que há uma base instalada de âmbito municipal capaz de responder cabalmente aos desafios de uma moderna gestão e disponibilização de dados geográficos.

\section{Modelos de negócio}

A construção e exploração de uma infraestrutura que promova o incremento do conhecimento territorial é imprescindível para o desenvolvimento. Mas a construção desta infraestrutura implica a necessária mudança de algumas perspetivas e paradigmas que ainda subsistem, senão veja-se:

- Não faz sentido não haver uma maior articulação do investimento público, por forma a assegurar a existência de uma série de conjuntos de dados geográficos estratégicos para o país, de qualidade, bem como a sua contínua atualização;

- Não faz sentido não haver uma maior descentralização do processo produtivo de conjuntos de dados geográficos vetoriais básicos, envolvendo diretamente os municípios ou as comunidades intermunicipais;

- Não faz sentido não haver condições de acesso aos conjuntos e serviços de dados geográficos estratégicos para o país que promovam a sua efetiva utilização pública, a criação de valor acrescentado e o suporte à investigação e docência;

- Não faz sentido não haver um maior aproveitamento e integração do contributo participativo dos cidadãos.

O caminho a percorrer e os passos a dar são conhecidos e Portugal tem de construir uma agenda para o fazer, não por os outros países já o estarem a praticar, mas para incrementar a sua competitividade e promover o desenvolvimento.

Um território bem pensado e gerido e uma administração ágil são peças imprescindíveis numa sociedade moderna. FERRão (2011:115) refere que "mais e melhor informação, conhecimento, organização e tecnologias inovadoras de suporte" são as componentes-chave que uma moderna política pública de ordenamento do território exige, o que aliás é concordante com a perspetiva de que a "boa gestão do território pressupõe a disponibilidade e difusão alargada de informação e de conhecimentos actualizados sobre os recursos existentes $e$ as dinâmicas e perspectivas de desenvolvimento às escalas nacional, regional e local" (MAOTDR, 2007: 221).

Mas hoje nada se pode fazer sem o envolvimento dos cidadãos. 0 território é deles, dos atuais e das gerações futuras. O conceito de Volunteered Geographic Information (VGI) cunhado por GoodCHILD (2007) é a consolidação de um movimento que emergiu a partir de meados da década passada usufruindo do avanço das plataformas tecnológicas e da crescente sensibilização de todos para consciencialização geográfica. No sentido de que tudo acontece algures e através da espacialização dos fenómenos e interesses, bem como da sua interação é possível melhor compreender, usufruir, potenciar e preservar o território.

Cabe no entanto ao Estado pensar e promover um modelo de organização que providencie o adequado ambiente colaborativo para fomentar a aquisição, gestão e exploração de conjuntos de dados geográficos relativos a temas estruturantes do território ou de elevado interesse para a Administração, muitos deles já preconizados no âmbito da Diretiva INSPIRE.

A criação deste ambiente passa necessariamente pela discussão e formalização de novos modelos de negócio que viabilizem económica e financeiramente a sua concretização. 0 atual sistema de financiamento da produção e gestão de dados geográficos impele os organismos públicos responsáveis por estas tarefas para uma atitude mercantilista, muitas vezes concorrencial, com os profundos efeitos negativos que todos acabamos por sentir.

No atual paradigma da sociedade da informação e conhecimento, as economias relacionadas com a informação são cruciais para o crescimento, competitividade e emprego, garantindo 
aos cidadãos uma melhor qualidade de vida enquadrada numa lógica de desenvolvimento sustentável. As infraestruturas de informação são os pilares deste novo paradigma (Castells e Himanen, 2002).

Os EUA, confirmando os bons resultados das iniciativas lançadas no final do século passado (entre outras a criação dos precursores ficheiros TIGER), vieram agora reafirmá- las, conforme se pode verificar pela nota disponibilizada pelo National States Geographic Information Council (NSGIC) em novembro de 2011 onde afirma que "strongly believes that open sharing of geospatial data is in the best interest of our communities, states and nation. One of our goals is to make all non-sensitive geospatial data, produced or maintained using taxpayer funds, a part of the public record" (NSGIC, 2011).

$\mathrm{Na}$ Europa, onde grande parte dos dados geográficos são criados e geridos por entidades públicas e sempre prevaleceu um modelo de cost-recovery ou mesmo de base comercial (do qual o exemplo paradigmático é o Ordnance Survey, UK), fruto das pressões da União Europeia (de que é um excelente exemplo a Diretiva 2003/98/EC sobre a reutilização dos dados do sector público, vulgarmente conhecida como Diretiva PSI) e de movimentos colaborativos (como por exemplo o Openstreetmap) começa a registar-se alguns sinais de mudança.

O Reino Unido lançou em 2008 a Location Strategy que, de acordo com o relatório que a sustenta, procura "maximise exploitation and benefit to the public, government and UK Industry from geographic information and to provide a framework to assist European, national, regional and local initiatives (...) build a coherent Information and Communication Technology (ICT) oriented information infrastructure for place-based information, which will assist policy, local service delivery and operational decision making" (GI PANEL, 2008: 10).

A Dinamarca, numa iniciativa enquadrada na estratégia de e-Government 2013-2016, estabelecida em conjunto pelo governo e municípios do país, reconhecendo o valor estratégico da informação geográfica e do livre acesso a esta por parte do sector público, das empresas e dos cidadãos, decidiu disponibilizar, desde 1 de janeiro de 2013, livre e gratuitamente, os dados topográficos, cartográficos, cadastrais e endereços.

A Islândia anunciou que a janeiro de 2013 "digital maps and Spatial Data held by the National Land Survey of Iceland has been made free of charge, as determined by Svandís Svavarsdóttir Environment and Natural Resources Minister. The data is used in various projects of state agencies such as registration, planning, nature conservation, natural hazards, energy, research and public projects, but they also benefit the public and businesses in various ways. The purpose of making digital maps and Spatial Data free of charge is to ensure that the general public in Iceland is guaranteed easy access to information about the environment and nature of Iceland. The goal is also to encourage increased use, processing and dissemination of this data, for example in the field of tourism, public administration and education" (LMI, 2013).

São apenas três exemplos de casos europeus onde já se consolidou o pensamento de que a informação geográfica é um pilar imprescindível da sua estratégia de competitividade e desenvolvimento, na linha do que há muito vem a ser defendido, designadamente pelos vários estudos e iniciativas de suporte à Diretiva PSI. É indubitável o valor acrescentado da informação geográfica de qualidade para o bom funcionamento da economia (LoENEN e ZEVENBERGEN, 2010).

\section{Conclusões}

Um território bem pensado e gerido e uma administração ágil são peças imprescindíveis numa sociedade moderna. Para o efeito há vários requisitos que têm de ser reunidos.

Como se viu a informação desempenha um papel crítico no suporte à correta e eficaz gestão do território, mas também é importante haver bases. Bases institucionais, metodológicas e tecnológicas. 


\section{Realidades e desafios na gestão dos riscos \\ - Diálogo entre ciência e utilizadores -}

O Guia aqui referido é um claro exemplo de sucesso do esforço conjunto entre a ciência e os utilizadores. Sem a conjugação do conhecimento e da investigação das universidades nacionais com a experiência dos serviços que estão no terreno, não seria obter uma base de apoio utilizável em contexto real.

No plano institucional, verifica-se que os serviços da administração pública podem ainda incrementar o seu potencial se melhor se explorar o potencial existente ao nível municipal.

Em Portugal, não obstante a iniciativa da Agência de Modernização Administrativa que vem disponibilizar num portal (www.dados.gov.pt) alguns dados produzidos pela Administração Pública para que possam ser acedidos e reutilizados, prevalecem os condicionalismos no que se refere aos dados geográficos, pois é quase nula a sua presença neste portal (resume-se a dois registos: rede de nivelamento geométrico e rede de geodésica nacional).

A iniciativa iGEO (www.igeo.pt), lançada em 2014, veio colmatar algumas lacunas ao nível da disponibilização de dados para efeitos de visualização, mas prevalece ainda o bloqueio na sua acessibilidade para efeitos de manipulação e análise. É este o grande salto que nos falta dar em Portugal, pois o Território é a base e só com a conjugação dos princípios anteriormente referidos e ilustrados e a implementação das políticas e instrumentos que lhes estão subjacentes é que será possível ter uma verdadeira gestão territorial no seu pleno sentido e uma sólida base de promoção da competitividade e desenvolvimento do País.

\section{Referências Bibliográficas}

Afonso, A.; Martins, F.; Dias, R.; Mendes, V.B. (2007) - O projecto SERVIR do IGeoE a suas aplicações, Cartografia e Geodesia 2007, J. CASACA e J. MATOs (Eds.). Lisboa, Lidel, Lda: p. 409-422.

Castells, M.; Himanen, P. (2002) - The Information Society and the Welfare State: The Finnish Model. New York, Oxford University Press, 200p.

Ferrão, J. (2011) - O Ordenamento do Território como Política Pública. Lisboa, Fundação Calouste Gulbenkian, 146 p.

Geirinhas, J.; Gomes, A.L.; Fonseca, A.; Santos, A.S.; Silva, H. e Julião, R.P. (2011) - "Aplicação da Directiva INSPIRE em Portugal - Monitorização 2011”, JIIDE 2011 - II Jornadas Ibéricas de Infra-estruturas de Dados Espaciais, ICC, Barcelona (Espanha).

GI PANEL (2008) - Place matters: the Location Strategy for the United Kingdom. Londres, Communities and Local Government Publications, 38p.

GoodCHILD, M.F. (2007) - Citizens as sensors: the world of volunteered geography". GeoJournal, 69 (4): p. 211-221.

Julião, R.P.; Nery, F.; Ribeiro, J.L.; Castelo Branco, M. e Zêzere, J.L. (2009) - Guia metodológico para a produção de cartografia municipal de risco e para a criação de Sistemas de Informação Geográfica (SIG) de base municipal. ISBN 978-989-96121-4-3, Lisboa, ANPC, 91p.

JuLIão, R.P.; Quelrós, M.I. (2009) - "Realidade Municipal face aos Sistemas de Informação Geográfica”, VII Congresso da Geografia Portuguesa, APG e CEGOT, Coimbra.

Julião, R.P. (2001) - Tecnologias de Informação Geográfica e Ciência Regional - Contributos Metodológicos para a Definição de Modelos de Apoio à Decisão em Desenvolvimento Regional. Doutoramento, Universidade Nova de Lisboa.

Loenen, B. Van; Zevenberben, J. (2010) - “Assessing Geographic Information Enhancement”. International Journal of Spatial Data Infrasrtuctures Research, 5: p. 244-266.

LMI (2013) - Digital cartography and geographic information NLSI made free of charge, disponível em: http://www.lmi.is/stafraen-kort-og-landupplysingar-lmi-gerd-gjaldfrjals/. 
Guia metodológico para a cartografia de risco.

Um produto do diálogo ciência/utilizadores

MAOTDR (2007) - PNPOT. Programa Nacional da Política de Ordenamento do Território. Lisboa, MAOTDR, $226 \mathrm{p}$.

MARTINS, C.; VAsconcelos, M. (2011) - "A evolução da RENEP: produtos, serviços e utilizadores", VII Conferência Nacional de Cartografia e Geodesia, Ordem dos Engenheiros, Porto.

NSGIC (2011) - Geospatial Data Sharing Guidelines for Best Practices, disponível em: http:// www.nsgic.org/public_resources/NSGIC_Data_Sharing_Guidelines_120211_Final.pdf.

PINA, C. (2011). A nova regulamentação da cartografia nos IGT. Lisboa, Ordem dos Engenheiros. 15p, disponível em: http://www.ordemengenheiros.pt/fotos/dossier_artigo/ carlospina17691005044de3c65b5f890.pdf.

Roque, C.; Neto, J.P. e Julião, R.P. (2007) - Cadastro Predial e Informação de base cadastral, Cartografia e Geodesia, J. CASACA e J. MATOS (Eds.). Lisboa, Lidel, Lda: p. 525-536.

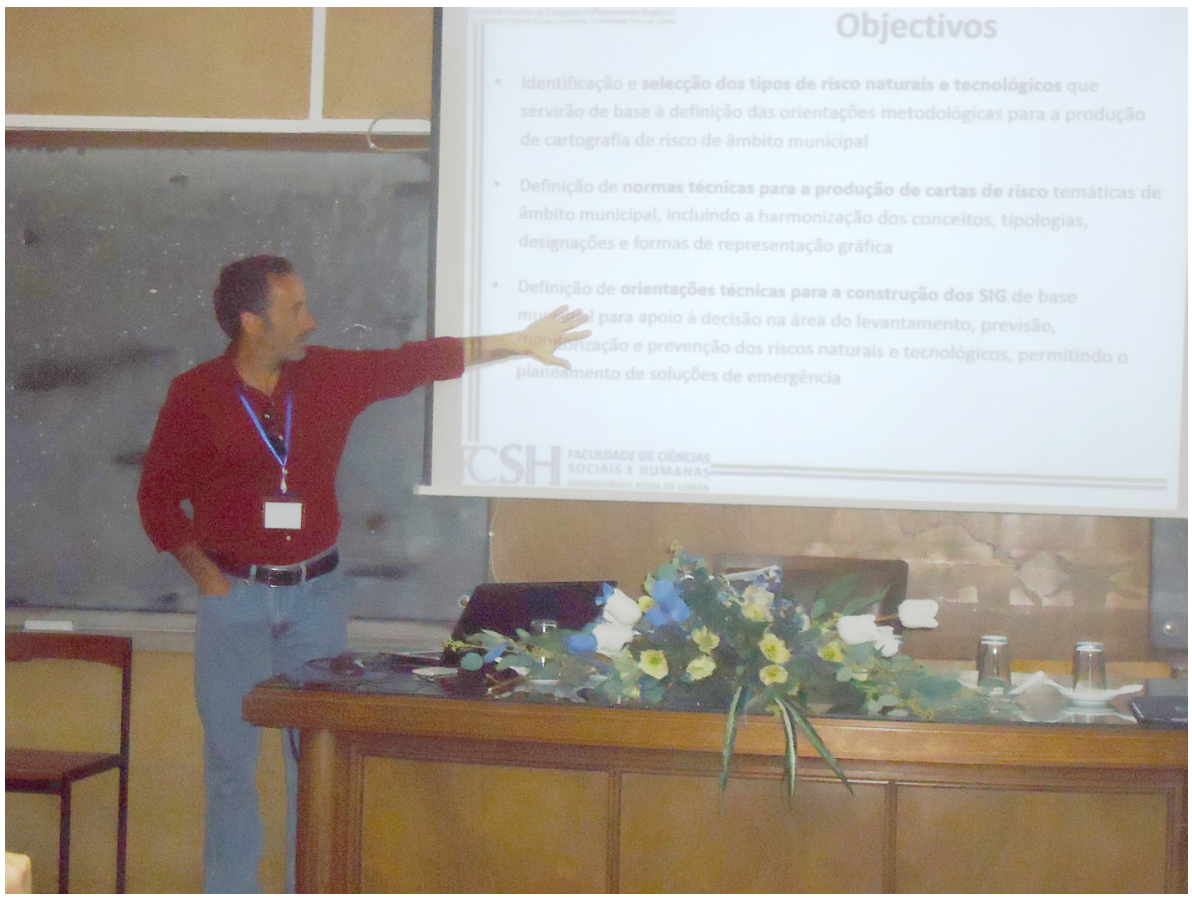

